\title{
SÉGRÉGATION ANORMALE POUR LES ALLELES " CRETTE SIMPLE " ET " CRÊTE EN ROSE "
}

\author{
PAR
}

\section{Ph. MERAT}

Station de Recherches Avicoles, Jouy-en-Josas. (S.-et-O.).

L'observation décrite ici concerne des déviations par rapport aux proportions théoriques, apparues plusieurs fois dans la ségrégation des allèles $\mathrm{R}$ (crête en rose) et $r$ (crête simple) dans un troupeau de volailles.

Sur des croisements (mâle $\mathrm{R} r \times$ femelle $r r$ ) ou (mâle $r r \times$ femelle $\mathrm{R} r$ ) répétés pendant plusieurs saisons d'élevage, les proportions de la descendance, observée à 8 semaines, par sexe, ont été les suivantes :

\begin{tabular}{|c|c|c|c|c|}
\hline \multirow{2}{*}{$\begin{array}{c}\text { Saison } \\
\text { d'élevage }\end{array}$} & \multicolumn{2}{|c|}{ Descendants mâles } & \multicolumn{2}{|c|}{ Femelles } \\
\hline & créte en rose & crête simple & crête en rose & crête simple \\
\hline Printemps 1954.... & 82 & $\mathrm{I}, 38$ & 103 & 93 \\
\hline Automne r $954 \ldots .$. & I I 3 & 155 & 1.33 & I2I \\
\hline Printemps $195, \ldots \ldots$ & 160 & 2.37 & 217 & 198 \\
\hline Printemps $195^{6} \ldots$. & 165 & 163 & I 55 & 172 \\
\hline Automne $5956 \ldots$ & $4^{2}$ & 40 & 37 & 40 \\
\hline Printemps $1957 \ldots$ & 10 & 17 & 18 & 24 \\
\hline Automne $5957 \ldots .$. & 15 & 14 & 23 & $3 \mathrm{I}$ \\
\hline Automne $1958 \ldots$ & 103 & II 3 & 108 & 85 \\
\hline
\end{tabular}

Alors que chez les femelles, la proportion crêtes en rose, crêtes simples ne s'écarte nulle part sensiblement de $I / I$, on constate un défaut très significatif (au seuil I p. Ioo) de mâles à crête en rose pour les trois premières saisons.

L'analyse de la descendance de chaque mâle hétérozygote $\mathrm{R} r$ montre des proportions anormales pour certains mâles, normales pour d'autres.

De même, certaines femelles $\mathrm{R} r$ ont des descendants mâles en proportion " normale ", d'autres pas. COCHEZ (communication personnelle) a observé également des proportions apparemment anormales dans certaines familles.

Sur les données présentes, l'écart aux proportions théoriques est difficilement explicable par une mortalité différentielle embryonnaire ou post-embryonnaire des deux catégories. 